\title{
Safety and efficacy of extending a previous endoscopic sphincterotomy for the treatment of retained or recurrent common bile duct stones
}

\author{
Antonios Vezakis ${ }^{a}$, Andreas Polydorou ${ }^{a}$, Elissaios Kontis ${ }^{b}$, Eirini Pantiora ${ }^{a}$, loannis S. Papanikolaou ${ }^{a}$, \\ Georgios Fragulidis ${ }^{a}$
}

National and Kapodistrian University of Athens, Aretaieion Hospital, Athens, Greece; Institute of Liver Studies, King's

College Hospital, Denmark Hill, London, UK

\section{Abstract}

\begin{abstract}
Background The aim of the study was to evaluate the safety and efficacy of extending a previous endoscopic sphincterotomy (ES) in patients with retained or recurrent common bile duct (CBD) stones.

Methods Between 2001 and 2013, extension of a previous ES, for known or suspected CBD stones, was performed in 118 patients (m/f, 53/65) with a median age of 74 (range: 31-91) years (group A). During the same period, ES was performed in 1064 patients with suspected or known choledocholithiasis (group B). The efficacy and complications of the extension (group A) were analyzed and a comparison was made between groups regarding complications.
\end{abstract}

Results Bile duct cannulation was straightforward in all patients in group A, while it was considered difficult in $49 \%$ of patients in group B. Complete clearance was achieved in 76/97 patients (78\%) with CBD stones, after a mean of 1.18 attempts per patient. Mechanical lithotripsy was required in $10 \%$ of patients. After extension, immediate bleeding occurred in 24 patients $(20 \%)$, which stopped spontaneously in $9(37 \%)$ and endoscopic hemostasis was required in the remainder. Complications were more frequent in group $\mathrm{B}(5.3 \%$ vs. $0.8 \%, \mathrm{P}=0.031)$, but there was no significant difference for any individual complication. Immediate bleeding was more common in group B ( $29 \%$ vs. $20 \%, \mathrm{P}=0.035)$, but there was no difference in clinical bleeding.

Conclusion Extension of a previous ES seems to be a simple, effective and safe technique, allowing stone clearance in nearly $80 \%$ of patients; it is thus recommended in patients with CBD stones after ES.

Keywords Endoscopic sphincterotomy, extension, choledocholithiasis, recurrent stones, balloon dilation, complications, sphincteroplasty, retained stones

Ann Gastroenterol 2017; 30 (6): 1-6
${ }^{\mathrm{a}} 2^{\text {nd }}$ Department of Surgery and Endoscopy Unit, National and Kapodistrian University of Athens, Aretaieion Hospital, Athens, Greece (Antonios Vezakis, Andreas Polydorou, Eirini Pantiora, Ioannis S. Papanikolaou, Georgios Fragulidis); ' Institute of Liver Studies, King's College Hospital, Denmark Hill, London, UK (Elissaios Kontis)

\section{Conflict of Interest: None}

Correspondence to: Ioannis S. Papanikolaou, MD, PhD, FEBGH, Assistant Professor in Internal Medicine-Gastroenterology, National and Kapodistrian University of Athens, Aretaieion Hospital, 76 Vas. Sofias Ave., 11528 Athens, Greece, e-mail: ispapn@hotmail.com

Received 23 July 2017; accepted 26 September 2017; published online 26 October 2017

DOI: https://doi.org/10.20524/aog.2017.0206

\section{Introduction}

Endoscopic retrograde cholangiopancreatography (ERCP) with endoscopic sphincterotomy (ES) has been established as a first-line treatment of choledocholithiasis. However, ES is associated with complications, such as bleeding, pancreatitis, and perforation, and long-term adverse events such as sphincter of Oddi dysfunction $[1,2]$. In an effort to avoid the adverse events of ES, endoscopic papillary balloon dilation has been introduced, but has not been established as a standard treatment because of the potential risk of severe pancreatitis [3].

Recurrent common bile duct (CBD) stone formation is not uncommon following ES, with an incidence ranging from 4-24\% [4-7]. Repeat ERCP with extension of the previous ES is 
often the treatment of choice for these patients [8]. Endoscopic papillary large balloon dilation (EPLBD) after a limited sphincterotomy has been recently established [9] with the intention of reducing complications and allowing the removal of large stones without the need for mechanical lithotripsy [10]. The aim of the present retrospective study was to assess the efficacy and safety of extending a previous ES for the treatment of recurrent or retained choledocholithiasis.

\section{Patients and methods}

A retrospective observational study was undertaken, extending over the years 2001-2013, based on data from a prospectively maintained database. This database includes 2520 ERCPs performed by a single operator (AV). Both demographic and clinical data are documented within this database.

In 118 cases with suspected or known choledocholithiasis, an extension of a previous ES was performed (group A). During the same period, ES was performed in 1064 patients with suspected or known choledocholithiasis (group B). Patients with malignancy were excluded. Antiplatelets (except aspirin) were discontinued for at least 5 days before the procedure. Acenocoumarol was discontinued for 2-3 days and perioperative bridging therapy with low molecular weight heparin was used.

Bile duct cannulation was defined as difficult when more than 5 attempts were required at cannulation, or when a needle-knife precut was performed. Sphincterotomies were performed using an endo-cut mode. Complications were defined according to the previous literature $[1,11]$. Immediate bleeding after ES was documented separately from bleeding that was clinically evident after the examination. Clinically evident bleeding was designated as hematemesis or melena, with an associated decrease in hemoglobin of at least $2 \mathrm{~g} / \mathrm{dL}$ or the need for blood transfusion [1,11].

A comparison was performed between groups regarding complications. The statistical analysis was conducted using the chi-square or Fisher's exact test for categorical variables and the Mann-Whitney test for non-parametric continuous variables. The study was reviewed by a biomedical biostatistician expert in medical data analysis. Minitab 16 Statistical Software was used for all calculations.

\section{Results}

Group A consisted of 53 male and 65 female patients with a median age of 74 (range: $31-91$ ) years. The most common presenting symptom was acute cholangitis, encountered in $71 \%$ of the patients, whereas $22 \%$ were asymptomatic. Asymptomatic patients had a scheduled repeat ERCP for stent or stone removal. The median interval from the previous ES was 7 months (range: 4 days to 20 years). Patients in group A were older, more often asymptomatic and were more likely to have undergone a previous biliary operation than those of group B, with cholecystectomy being the most common procedure $(90 \%)$. There was no patient with acute pancreatitis as a presenting symptom in group A. Patient characteristics are shown in Table 1.

As expected, bile duct cannulation was straightforward in all patients in group A, while it was considered difficult in almost half $(49 \%)$ the patients in group B. The median CBD diameter in group A patients was 13 (range: 8-20) $\mathrm{mm}$. The pancreatic duct was opacified in only 12 patients (10\%), as cannulation of the pancreatic duct was not intended in patients of group A. CBD stones were found in 97 (82\%) patients. The remaining 21 patients had dilated ducts with no visible stones and the extension was performed because of suspected stenosis of the previous ES. Thirty-three patients (34\%) had CBD stones larger than $15 \mathrm{~mm}$. Complete CBD clearance of stones was achieved at the first attempt in $76 / 97$ patients (78\%); a second attempt was required in 11 and a third in 3 patients. Mechanical lithotripsy was required in 10 patients (10\%), whereas further extension of a previously extended ES was required in 7 patients, at the second or third attempt. Despite these therapeutic maneuvers, surgical CBD exploration in order to remove the stones was required in 15 patients (15\%). Additionally, there were 27 patients with stones after ES, in whom an extension was not required to remove the stones; in 4 of them EPLBD was performed. These patients were excluded from our analysis. The outcome of patients with CBD stones is shown in Table 2.

Immediate bleeding, after extension, occurred in 24 patients (20\%). Although it stopped spontaneously in $9(37 \%)$, adrenaline injection or combination with other hemostatic techniques (argon plasma coagulation, application of diathermy, balloon tamponade) was required in 15/24 (62\%) patients. Endoscopic hemostasis was achieved in all but one patient, who underwent a laparotomy for hemostasis. There was no difference regarding age, sex, time interval from previous ES, presence of CBD stones, duodenal diverticula or cholangitis, antiplatelet or acenocoumarol use, between patients who presented immediate bleeding in comparison with patients who did not have any bleeding complication (Table 3). An American Society of Anesthesiologists' (ASA) score $\geq 3$ was the only factor associated with increased immediate bleeding after extension. There were no other complications in that group of patients. Two post-ERCP deaths occurred, but these were due to cardiovascular events, not directly related to the procedure. Complications are listed in Table 4. Complications were more frequent in group B (5.3\% vs. $0.8 \%)$. There were 3 deaths in group B, but none was directly related to the procedure itself.

\section{Discussion}

CBD stones found 6 months or more after ERCP with ES are generally considered recurrent, as opposed to retained $[5,6,12,13]$. Risk factors for recurrent CBD stones are mainly periampullary diverticula and a dilated CBD. Other factors that have been identified include advanced age, 
Table 1 Baseline characteristics of the patients

\begin{tabular}{|c|c|c|c|}
\hline Characteristic & Group A & Group B & P-value \\
\hline $\mathrm{n}$ & 118 & 1064 & \\
\hline $\operatorname{Sex}(m / f)$ & $53 / 65$ & $487 / 577$ & NS (C-S) \\
\hline Age (median, range) & $74(31-91)$ & $73(16-99)$ & $0.039(\mathrm{M}-\mathrm{W})$ \\
\hline ASA score I, II / $\geq$ III & $90 / 28$ & $750 / 238$ & NS (C-S) \\
\hline \multicolumn{4}{|l|}{ Symptomatology } \\
\hline Asymptomatic & $27(22 \%)$ & $41(4 \%)$ & $<0.0005$ (C-S) \\
\hline Acute cholangitis & $84(71 \%)$ & $785(76 \%)$ & NS \\
\hline Biliary colic & $7(6 \%)$ & $55(5.3 \%)$ & NS \\
\hline Acute pancreatitis & 0 & $149(14 \%)$ & $<0.0005$ (C-S) \\
\hline Previous biliary operation & $86(72 \%)$ & $363(34 \%)$ & $<0.0005$ (C-S) \\
\hline Antiplatelets & $12(10 \%)$ & $93(8.7 \%)$ & NS (C-S) \\
\hline Acenocoumarol & $3(2.5 \%)$ & $45(4.2 \%)$ & NS (C-S) \\
\hline Duodenal diverticula & $26(22 \%)$ & $261(24.5 \%)$ & NS (C-S) \\
\hline
\end{tabular}

Table 2 Outcomes of patients with recurrent or retained CBD stones

\begin{tabular}{lc}
\hline Technique and outcome & $\begin{array}{c}\text { No. of patients } \\
(\mathrm{n}=124)\end{array}$ \\
\hline No extension & 23 \\
EPLBD & 4 \\
Extension ES & 97 \\
Stone size $\geq 15 \mathrm{~mm}$ & $33(34 \%)$ \\
Complete CBD clearance after extension & $76(78 \%)$ \\
Mechanical lithotripsy & $10(10 \%)$ \\
Surgical CBD exploration & $15(15 \%)$ \\
Lost to follow up & 2 \\
Laparotomy for bleeding & 1 \\
Death & 2 \\
Stents as definite treatment & 1 \\
\hline
\end{tabular}

CBD, common bile duct; ES, endoscopic sphincterotomy; $n$, number of patients; EPLBD, endoscopic papillary large balloon dilation

previous biliary surgery and CBD angulation [14-17]. A dilated CBD may contribute to stone recurrence by bile stagnation and bacteriobilia, while periampullary diverticula promote stone formation by a combination of bacterial overgrowth and motility disturbance $[18,19]$. Our observations are in line with the literature, as our group A patients had high percentages of these risk factors: median CBD diameter was $13 \mathrm{~mm}$, ranging from $8-20 \mathrm{~mm}$, and the incidence of periampullary diverticula was $22 \%$. On the other hand, in our cohort, the median interval from the previous ES was 7 months (ranging from 4 days to 20 years). Thus, a point of criticism could be that all stones in our cohort were not recurrent, as the interval was sometimes as short as 4 days. It is our policy to repeat the ERCP at 3 months after placing pigtail stents for drainage when complete CBD clearance has not been achieved.

As age is considered a risk factor for the recurrence of stones, it should be pointed out that patients in group A were marginally older (74 vs. 73 years); however, we consider this statistical difference to be secondary to the inequality of the patients included in our cohort rather than a true clinical difference. In addition, the majority of them had a previous cholecystectomy, as the primary ES is usually followed by cholecystectomy. No patient in group A presented with acute pancreatitis, because after ES the pancreatic orifice is away from the biliary opening and stones can pass to the duodenum without causing pancreatitis [20].

Although extension of ES may appear straightforward, it cannot always be extended, because the anatomical landmarks for guiding the incision are sometimes obscure. When the previous ES is already large enough or inside a diverticulum, it can be considered that there is no space for extension. In 27 of our patients with stones after ES, no extension was performed because either the ES was considered of sufficient length and the stones were removed with standard techniques (23 patients), or EPLBD was performed (4 patients). During the study period, EPLBD had just started to be implemented in our department, thus precluding a comparison of ES extension and EPLBD, which might otherwise have been interesting. Thus, the aforementioned 27 patients were excluded from our analysis. Finally, complete CBD clearance was achieved in 78\% of patients after several attempts (mean 1.18 per patient) and the use of mechanical lithotripsy in $10 \%$.

Following ES, the size of the incision shrinks over time $[21,22]$. In addition, the formation of scar tissue may cause difficulties during extension or make it uncontrollable. This in turn, could increase the incidence of bleeding or perforation. Extension of a previous ES has been reported as a risk factor 
Table 3 Comparisons between patients who presented immediate bleeding or not after extension of previous ES (group A)

\begin{tabular}{|c|c|c|c|}
\hline \multirow[t]{3}{*}{ Variable } & \multicolumn{2}{|c|}{ Immediate bleeding } & \multirow[t]{3}{*}{ P-value } \\
\hline & Yes & No & \\
\hline & $\mathrm{n}=24$ & $\mathrm{n}=94$ & \\
\hline Age (median, range) & $73.5(41-89)$ & $74(31-82)$ & NS $(M-W)$ \\
\hline $\operatorname{Sex}(m / f)$ & $11 / 13$ & $42 / 52$ & NS (C-S) \\
\hline ASA score $\geq$ III & $1(4 \%)$ & $25(26 \%)$ & $0.018(\mathrm{C}-\mathrm{S})$ \\
\hline Interval from previous ES (months: median, range) & $20(0.5-80)$ & $6(0.1-244)$ & NS $(M-W)$ \\
\hline Antiplatelets & $2(8 \%)$ & $10(10 \%)$ & NS (C-S) \\
\hline Acenocoumarol & 0 & $3(3 \%)$ & NS (C-S) \\
\hline CBD stones & $21(87 \%)$ & $76(80 \%)$ & NS (C-S) \\
\hline $\mathrm{DD}$ & $4(16 \%)$ & $22(23 \%)$ & NS (C-S) \\
\hline Cholangitis & $15(62 \%)$ & $69(73 \%)$ & NS (C-S) \\
\hline
\end{tabular}

ES, endoscopic sphincterotomy; NS, non-significant; $M$-W, Mann-Whitney; C-S, chi-square; CBD, common bile duct; DD, duodenal diverticula; ASA, American Society of Anesthesiologists

Table 4 Comparison of complication rate between groups

\begin{tabular}{|c|c|c|c|}
\hline Complication & $\begin{array}{l}\text { Group A } \\
(\mathrm{n}=118)\end{array}$ & $\begin{array}{l}\text { Group B } \\
(n=1064)\end{array}$ & $\begin{array}{l}\text { P-value } \\
\text { (C-S) }\end{array}$ \\
\hline Acute pancreatitis & 0 & $22(2 \%)$ & NS \\
\hline Immediate bleeding & $24(20 \%)$ & $315(29 \%)$ & 0.035 \\
\hline Endoscopic hemostasis & $15(62 \%)$ & $228(72 \%)$ & NS \\
\hline Clinical bleeding & $1(0.8 \%)$ & $16(1.5 \%)$ & NS \\
\hline Laparotomy & $1(0.8 \%)$ & 0 & NS \\
\hline Acute cholangitis & 0 & 3 & NS \\
\hline Acute cholecystitis & 0 & 3 & NS \\
\hline Perforation & 0 & $13(1.2 \%)$ & NS \\
\hline ERCP-related death & 0 & 0 & NS \\
\hline Total clinical complications ${ }^{*}$ & $1(0.8 \%)$ & $57(5.3 \%)$ & 0.031 \\
\hline
\end{tabular}

ERCP, endoscopic retrograde cholangiopancreatography; NS, non significant; C-S, Chi-square or Fisher's exact test as appropriate

( ${ }^{*}$ Total clinical complications do not include "immediate bleeding" and "endoscopic hemostasis").

for bleeding [23,24], the reason being the increased chance of cutting the larger blood vessels around the distal bile duct and the increased vascularization at the previous ES site. It has also been suggested that the incidence of bleeding increases when the extension is performed early after the primary ES [25]. In contrast, extension was not identified as a risk factor for bleeding by Freeman et al [1]. In our study, immediate bleeding was less frequent after extension rather than primary ES (20\% vs. $29 \%$ ) and there were also fewer episodes of clinical bleeding ( $0.8 \%$ vs. $1.5 \%)$, although this difference did not achieve statistical significance (Table 4 ). The lower incidence of immediate bleeding may be associated with the shorter incision performed in patients with previous ES (group A) and to an edematous papilla after the previous cannulation attempts in primary ES patients (group B). The incidence of required endoscopic hemostasis in patients with immediate bleeding was statistically similar between the two groups (62\% vs. $72 \%$ ) (Table 4). In our study, bleeding after extension was not associated with the time interval from the previous ES. The only factor associated with increased immediate bleeding was an ASA score $\geq 3$. It seems that patients with associated severe comorbidities tend to bleed easily.

Acute pancreatitis occurred in $2 \%$ of patients in group B, while there was no such complication after extension. This is probably due to the ease of cannulation through the previous ES and to the separation of the biliary opening and pancreatic orifice, so that the cutting would be away from the pancreatic sphincter. Despite the fear of uncontrolled incision with no clear landmarks, there was no perforation in group A patients. The incidence of perforation in group B patients seems high (1.2\%), but half of them were guidewire perforations due to cannulation attempts, with no clinical significance. The low 
overall incidence of complications $(0.8 \%)$ makes extension even safer than the initial sphincterotomy, in agreement with previous reports [25].

Two patients died after extension, one from myocardial infarction in the recovery room and the other from pneumonic embolism 7 days after the procedure. Three patients died in group B. Two of them (critically ill patients, already in the Intensive Care Unit), underwent ERCP-ES for severe pancreatitis with biliary obstruction and died as a consequence of the pancreatitis. The third one died of cardiac failure, two days after the procedure. Hence, it is evident that none of the mortality events in our study was directly related to the procedure itself.

Overall complications were more frequent in group B $(5.3 \%$ vs. $0.8 \%)$. However, we believe that this appears to be a cumulative effect, as we failed to identify any specific complication which was significantly more prominent in either group. A possible exception to this might be the occurrence of endoscopically diagnosed bleeding, which was more common among patients in group B; however, this difference did not correlate with the occurrence of clinically evident bleeding.

EPLBD is an alternative technique to ES extension that involves dilation of the biliary sphincter with a large-diameter $(\geq 12 \mathrm{~mm})$ balloon $[9,26]$. EPLBD in combination with ES versus ES alone have similar outcomes in terms of stone clearance, with less use of mechanical lithotripsy and a lower risk of overall adverse events $[10,27,28]$.

In patients with stones after a previous ES, treatment is controversial. In some of them (19\% in our study) the stones can be removed using only standard balloon or basket techniques. In the remaining cases, a widening of the biliary orifice is required to achieve stone clearance, because of either stone size or ES shrinkage. To the best of our knowledge, there are no randomized studies comparing ES extension with EPLBD in these patients. The only existing evidence comes from case series and retrospective studies [29-32]. In these studies, patients with stones that were difficult to extract underwent EPLBD. However, these studies were inhomogeneous in various aspects, including the definition of difficulty and the size of difficult stones, which ranged from $\geq 10$ to $\geq 12 \mathrm{~mm}$ or even larger. Complete clearance was achieved in nearly all patients with minor complications, but lithotripsy (mechanical, laser, electrohydraulic) was required in 30\% [32]. In our study, complete clearance was achieved in $78 \%$ of cases after extension, with a need for mechanical lithotripsy in $10 \%$. The high incidence of surgical exploration (15\%) in our study was attributed to the lack of electrohydraulic or laser lithotripsy in our department and to the referring surgeon's preference. Laparoscopic or open CBD exploration remains an alternative to repeated ERCPs in surgically fit patients [33]. Naturally, offering this alternative to a patient warrants sound clinical judgment. In our series, all patients who underwent surgical exploration had stones larger than $15 \mathrm{~mm}$.

The limitations of our study include its retrospective design, as well as the inequality of the sample size between the two groups. However, performing a study with equal numbers of patients in the two groups, given the difference in occurrence of de novo choledocholithiasis (which is more common) and

\section{Summary Box}

\section{What is already known:}

- Endoscopic retrograde cholangiopancreatography with endoscopic sphincterotomy (ES) is the firstline treatment of choledocholithiasis

- ES is associated with complications, including bleeding, pancreatitis and perforation; to avoid such adverse events, endoscopic papillary balloon dilation is being extensively used, but also carries the risk of pancreatitis

- Recurrent or remnant common bile duct stones are not uncommon; their treatment can be facilitated either by balloon dilation or by extension of a previous ES

\section{What the new findings are:}

- Extension of a previous ES is even safer than primary ES, with fewer overall complications

- Extension of a previous ES allows common bile duct stone clearance in nearly $80 \%$ of patients

recurrent CBD stones would have to include some degree of selection bias. Another limitation that we must acknowledge is the inability to distinguish complications related to cannulation attempts or ES in group B, in order to make a better comparison to group A complications.

In conclusion, extension of a previous ES, in experienced hands, seems to be a simple, effective and safe technique allowing stone clearance in nearly $80 \%$ of patients. Therefore, patients with stones after ES, either recurrent or retained, which cannot be extracted with standard techniques should be considered for ES extension. Further studies, including randomized controlled trials, will be required to define the role of EPLBD in these patients.

\section{References}

1. Freeman ML, Nelson DB, Sherman S, et al. Complications of endoscopic biliary sphincterotomy. N EnglJ Med 1996;335:909-918.

2. Freeman ML. Complications of endoscopic biliary sphincterotomy: a review. Endoscopy 1997;29:288-297.

3. Weinberg BM, Shindy W, Lo S. Endoscopic balloon sphincter dilation (sphinteroplasty) versus sphincterotomy for common bile duct stones. Cochrane Database Syst Rev 2006;(4):CD004890.

4. Prat F, Malak NA, Pelletier G, et al. Biliary symptoms and complications more than 8 years after endoscopic sphincterotomy for choledocholithiasis. Gastroenterology 1996;110:894-899.

5. Bergman JJ, van der Mey S, Rauws EA, et al. Long-term follow-up after endoscopic sphincterotomy for bile duct stones in patients younger than 60 years of age. Gastrointest Endosc 1996;44:643-649.

6. Keizman D, Ish Shalom M, Konikoff FM. Recurrent symptomatic 
common bile duct stones after endoscopic stone extraction in elderly patients. Gastrointest Endosc 2006;64:60-65.

7. Langerth A, Brandt L, Ekbom A, Karlson BM. Late complications following endoscopic sphincterotomy for choledocholithiasis: A Swedish Population-Based Study. Diagn Ther Endosc 2014;2014:745790.

8. Sugiyama M, Suzuki Y, Abe N, Masaki T, Mori T, Atomi Y. Endoscopic retreatment of recurrent choledocholithiasis after sphincterotomy. Gut 2004;53:1856-1859.

9. Ersoz G, Tekesin O, Ozutemiz AO, Gunsar F. Biliary sphincterotomy plus dilation with a large balloon for bile duct stones that are difficult to extract. Gastrointest Endosc 2003;57:156-159.

10. Stefanidis G, Viazis N, Pleskow D, et al. Large balloon dilation vs. mechanical lithotripsy for the management of large bile duct stones: a prospective randomized study. Am J Gastroenterol 2011;106:278-285.

11. Cotton PB, Lehman G, Vennes J, et al. Endoscopic sphincterotomy complications and their management: an attempt at consensus. Gastrointest Endosc 1991;37:383-393.

12. Ueno N, Ozawa Y, Aizawa T. Prognostic factors for recurrence of bile duct stones after endoscopic treatment by sphincter dilation. Gastrointest Endosc 2003;58:336-340.

13. Tanaka M, Takahata S, Konomi H, et al. Long-term consequence of endoscopic sphincterotomy for bile duct stones. Gastrointest Endosc 1998;48:465-469.

14. Kim DI, Kim MH, Lee SK, et al. Risk factors for recurrence of primary bile duct stones after endoscopic biliary sphincterotomy. Gastrointest Endosc 2001;54:42-48.

15. Pereira-Lima JC, Jakobs R, Winter UH, et al. Long-term results (7 to 10 years) of endoscopic papillotomy for choledocholithiasis. Multivariate analysis of prognostic factors for the recurrence of biliary symptoms. Gastrointest Endosc 1998;48:457-464.

16. Sugiyama M, Atomi Y. Risk factors predictive of late complications after endoscopic sphincterotomy for bile duct stones: longterm (more than 10 years) follow-up study. Am J Gastroenterol 2002;97:2763-2767.

17. Keizman D, Shalom MI, Konikoff FM. An angulated common bile duct predisposes to recurrent symptomatic bile duct stones after endoscopic stone extraction. Surg Endosc 2006;20:1594-1599.

18. Løtveit T, Osnes M, Aune S, Larsen S. Studies of the choledochoduodenal sphincter in patients with and without juxta-papillary duodenal diverticula. Scand J Gastroenterol 1980;15:875-880.

19. Skar V, Skar AG, Osnes M. The duodenal bacterial flora in the region of papilla of Vater in patients with and without duodenal diverticula. Scand J Gastroenterol 1989;24:649-656.
20. van Geenen EJ, van der Peet DL, Mulder CJ, Cuesta MA, Bruno MJ. Recurrent acute biliary pancreatitis: the protective role of cholecystectomy and endoscopic sphincterotomy. Surg Endosc 2009;23:950-956.

21. Geenen JE, Toouli J, Hogan WJ, et al. Endoscopic sphincterotomy: follow-up evaluation of effects on the sphincter of Oddi. Gastroenterology 1984;87:754-758.

22. Sugiyama M, Atomi Y. Longterm effects of endoscopic sphincterotomy on gall bladder motility. Gut 1996;39:856-859.

23. Goodall RJ. Bleeding after endoscopic sphincterotomy. Ann R Coll Surg Engl 1985;67:87-88.

24. Leung JW, Chan FK, Sung JJ, Chung SC. Endoscopic sphincterotomy-induced hemorrhage: A study of risk factors and the role of epinephrine injection. Gastrointest Endosc 1995;42:550-554.

25. Mavrogiannis C, Liatsos C, Papanikolaou IS, et al. Safety of extension of a previous endoscopic sphincterotomy: a prospective study. Am J Gastroenterol 2003;98:72-76.

26. Maydeo A, Bhandari S. Balloon sphincteroplasty for removing difficult bile duct stones. Endoscopy 2007;39:958-961.

27. Kim JH, Yang MJ, Hwang JC, Yoo BM. Endoscopic papillary large balloon dilation for the removal of bile duct stones. World $J$ Gastroenterol 2013;19:8580-8594.

28. Jin PP, Cheng JF, Liu D, Mei M, Xu ZQ, Sun LM. Endoscopic papillary large balloon dilation vs endoscopic sphincterotomy for retrieval of common bile duct stones: a meta-analysis. World $J$ Gastroenterol 2014;20:5548-5556.

29. Kurita A, Maguchi H, Takahashi K, Katanuma A, Osanai M. Large balloon dilation for the treatment of recurrent bile duct stones in patients with previous endoscopic sphincterotomy: preliminary results. Scand J Gastroenterol 2010;45:1242-1247.

30. Kim KO, Kim TN, Lee SH. Endoscopic papillary large balloon dilation for the treatment of recurrent bile duct stones in patients with prior sphincterotomy. J Gastroenterol 2010;45:1283-1288.

31. Harada R, Maguchi H, Takahashi K, et al. Large balloon dilation for the treatment of recurrent bile duct stones prevents short-term recurrence in patients with previous endoscopic sphincterotomy. J Hepatobiliary Pancreat Sci 2013;20:498-503.

32. Yoon HG, Moon JH, Choi HJ, et al. Endoscopic papillary large balloon dilation for the management of recurrent difficult bile duct stones after previous endoscopic sphincterotomy. Dig Endosc 2014;26:259-263.

33. Dasari BV, Tan CJ, Gurusamy KS, et al. Surgical versus endoscopic treatment of bile duct stones. Cochrane Database Syst Rev 2013;(12):CD003327. 